\title{
Prevalence and Antibiotic Resistance Pattern of Methicillin Resistant Staphylococcus aureus Isolates in a Tertiary Care Hospital
}

\author{
R. Uma Maheswari ${ }^{1 *}$, B. Cinthujah ${ }^{1}$, G. Sucilathangam ${ }^{2}$ and C. Revathy ${ }^{1}$ \\ ${ }^{1}$ Department of Microbiology, Tirunelveli Medical College, \\ Tirunelveli - 627 011, Tamil Nadu, India \\ ${ }^{2}$ Department of Microbiology, Government Theni Medical College, \\ Theni - 625512, Tamil Nadu, India \\ *Corresponding author
}

\section{Ke y w o r d s \\ Methicillin resistant Staphylococcus aureus (MRSA Community and Hospital acquired infections ,Disk diffusion Method, Antibiotic susceptibility testing}

\section{Article Info}

Accepted:

07 January 2019

Available Online:

10 February 2019

\section{A B S T R A C T}

Methicillin resistant Staphylococcus aureus (MRSA) is one of the most important etiology of community and hospital acquired infections. With an increasing incidence of Methicillin resistant Staphylococcus aureus (MRSA), the aim of the present study was to determine the prevalence of Methicillin resistant Staphylococcus aureus strains and their antibiotic susceptibility pattern in a tertiary care Hospital between July 2017 and July 2018. In this prospective cross sectional study, 100 Staphylococcus aureus were isolated and identified conventionally from various clinical specimens collected from different departments of the hospital. Subsequently, antimicrobial susceptibility test was performed by Kirby Bauer disc diffusion method as per Clinical and Laboratory Standards Institute (CLSI) guidelines. Among the $100 \mathrm{~S}$. aureus isolates, MRSA was found to be $54 \%$ by cefoxitin $(30 \mu \mathrm{g})$ disk diffusion method out of which maximum numbers were isolated from the age group of more than 60 years i.e. 14 isolates $(25.92 \%)$ predominantly in males. Among the $54 \%$ of MRSA isolated, maximum $44.44 \%$ were from pus, $18.53 \%$ from blood, $11.11 \%$ each from sputum, urine and drain and $1.85 \%$ each from Ascitic fluid and tracheal aspirate. Among the MRSA isolated, 33.33\% were from Surgery which was the highest followed by $27.78 \%$ from IMCU, $18.52 \%$ from Orthopaedics, $9.26 \%$ from Dermatology and 5.56\% from Burns ward. All the isolates were resistant to Penicillin and Cephalexin, followed by Tetracycline (22 isolates), Erythromycin (21 isolates), Clindamycin and Cotrimoxazole 19 isolates each, Gentamicin (18 isolates), Ciprofloxacin (17 isolates) and Amikacin (15 isolates). All the isolates were sensitive to Vancomycin, Linezolid and Teicoplanin. Inducible Clindamycin resistance was detected in 13 isolates (24\%) among MRSA isolates. Due to increasing development of resistance to multiple antibiotics, there is an increased need to find out the prevalence of MRSA and their current antimicrobial profile in order to provide appropriate therapy to the patients. 


\section{Introduction}

The emergence of antibiotic resistance is a health problem worldwide and has affected the management and outcome of wide spectrum of infections. It contributes to significant mortality and morbidity and remains a hindrance to the control of infectious diseases. It leads to increase in health associated expenses and also acts as a barrier in the healthcare security of countries.

Globally, Staphylococcus aureus (S.aureus) is considered as one of the most common cause of nosocomial infections (Rajesh Bhatia, 2008). This remains as the hardiest of the non-sporing bacteria and can survive well in the environment under both moist and dry conditions. The high prevalence of S.aureus, together with its propensity to infiltrate tissues, colonize foreign material, form abscesses and produce toxins, makes it by far the most feared micro-organism in healthcareassociated infections.

In recent times, there is a steady rise in the number of S.aureus isolates that show resistance to Methicillin and has evolved as a serious problem since resistance to this drug indicates resistance to all $\beta$-lactam antibiotics. (Multiple use of antibiotics and prolonged hospitalisation are important factors which make hospital an ideal place for transmission and perpetuation of Methicillin Resistant S.aureus (MRSA) (Blot et al., 2002). For these above reasons, accuracy and promptness in the detection of Methicillin resistance plays a key role for good prognosis of infections and hence abrupting its transmission (Chambers, 1997).

Hence the present study was undertaken to determine the prevalence of Methicillin resistant Staphylococcus aureus strains and their antibiotic susceptibility pattern in a tertiary care Hospital.

\section{Materials and Methods}

\section{Study population}

\section{Inclusion criteria}

Culture positive for Staphylococcus aureus. Only samples from hospitalized patients are included in the study.

\section{Exclusion criteria}

Samples from out patients are excluded from the study.

Samples from paediatric populations (less than 12 years)

\section{Sample collection and processing}

A total of 100 Staphylococcus aureus isolates from blood, urine, sputum, pus, wound swab, throat swab, nasal swab and endotracheal aspirates were taken for the study. All the samples were collected under aseptic precautions by standard procedures. They were then processed according to the standard guidelines. The specimens were inoculated on to nutrient agar (NA), MacConkey agar (MA), Blood agar (BA) and Mannitol Salt Agar (MSA). The media were incubated at $37^{0} \mathrm{C}$ overnight. The growth was identified by its characteristic colony morphology, Gram staining (gram positive cocci in clusters) and Coagulase test positivity.

All the isolated S.aureus strains were subsequently tested for methicillin resistance based on Kirby-Bauer disk diffusion method on Muller Hinton Agar using Cefoxitin $(30 \mu \mathrm{g})$ disk obtained from $\mathrm{Hi}$ Media laboratories, Mumbai, India. The isolates were considered to be Methicillin resistant if the zone of inhibition is equal to $22 \mathrm{~mm}$ or less. Further, DD method was performed with the following antibiotic disks like Penicillin

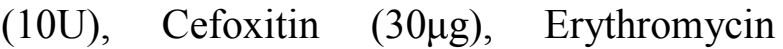
$(15 \mu \mathrm{g})$, Clindamycin $(2 \mu \mathrm{g}), \quad$ Gentamicin 
$(10 \mu \mathrm{g}), \quad$ Amikacin $\quad(30 \mu \mathrm{g}), \quad$ Vancomycin $(30 \mu \mathrm{g})$, Ciprofloxacin $(5 \mu \mathrm{g})$, Cotrimoxazole $(1.25 / 23.75 \mu \mathrm{g})$, Teicoplanin $(30 \mu \mathrm{g})$, Linezolid $(30 \mu \mathrm{g})$. Finally, the data were recorded and analysed at the completion of the study as per CLSI guidelines. S.aureus ATCC 25923 was used as a reference strain for the standardization of antibiotic susceptibility testing (CLSI, 2009).

\section{Results and Discussion}

Among $100 \mathrm{~S}$. aureus isolates 46 isolates (46\%) were MSSA and 54 isolates (54\%) were MRSA (Table 1). Among the 100 isolates, maximum number of MRSA maximum numbers was isolated from the age group of more than 60 years i.e. 14 isolates (25.92\%) followed by age group of 41-50 years i.e.11 isolates $(20.37 \%)$. Males outnumbered the females in the rate of isolation of MRSA. The sex ratio (male: female) was 1.25: 1 for MRSA (Table 1 and 2).

Among the $54 \%$ of MRSA isolated, $44.44 \%$ were from pus, $18.53 \%$ from blood, $11.11 \%$ each from sputum, urine and drain and $1.85 \%$ each from Ascitic fluid and tracheal aspirate (Table- 3). Among the 54\% of MRSA isolated,33.33\% were from Surgery which was the highest followed by $27.78 \%$ from IMCU, $18.52 \%$ from Orthopaedics,9.26\% from Dermatology, 5.56\% from Burns ward and $1.85 \%$ each from Urology, Thoracic Medicine and Ophthalmology wards. There were no isolates from Nephrology ward (Table 4).

\section{Antibiotic resistance pattern of MRSA strains}

All the isolates were resistant to Penicillin and Cephalexin, followed by Tetracycline (22 isolates), Erythromycin (21 isolates), Clindamycin and Cotrimoxazole 19 isolates each, Gentamicin (18 isolates), Ciprofloxacin (17 isolates) and Amikacin (15 isolates). All the isolates were sensitive to Vancomycin, Linezolid and Teicoplanin (Table-5).

Inducible Clindamycin resistance among MRSA isolates which was found to be 13.A MRSA isolate is considered to be multi drug resistant if resistance was noted among 3 or more than 3 drugs. Among the MRSA isolates, $14(25.93 \%)$ were resistant to more than or equal to 3 drugs, 12 isolates (22.22\%)for 4 drugs, 5 isolates $(9.26 \%)$ for 5 drugs and 7 isolates (12.96\%) were resistant for more than 6 drugs.

Antibiotic resistance among Staphylococcus aureus have been increasing day by day. The outbreaks of nosocomial infections and emergence of antimicrobial resistance and its epidemiological complexity have made resistant strains of S.aureus a remarkable organism. They are now considered as one of the important nosocomial pathogens. Resistance pattern among this pathogen may vary widely from place to place even within the same country over time. Hence the early detection of Methicillin resistance is of prime importance in prevention of nosocomial outbreaks (Salgado et al., 2003).

Table.1 Percentage of MSSA and MRSA among Staphylococcus aureus isolates

\begin{tabular}{|l|l|l|}
\hline Staphylococcus aureus & Number & Percentage (\%) \\
\hline MSSA & 46 & 46 \\
\hline MRSA & 54 & 54 \\
\hline Total & 100 & 100 \\
\hline
\end{tabular}


Table.2.1 Analysis by age and gender

\begin{tabular}{|c|c|c|}
\hline \multirow{2}{*}{$\begin{array}{r}\text { Age group } \\
\text { (In years) }\end{array}$} & \multicolumn{2}{|c|}{ MRSA } \\
\hline & Number & Percentage $(\%)$ \\
\hline$<20$ & 3 & 5.56 \\
\hline $21-30$ & 8 & 14.81 \\
\hline $31-40$ & 9 & 16.67 \\
\hline $41-50$ & 11 & 20.37 \\
\hline $51-60$ & 9 & 16.67 \\
\hline$>60$ & 14 & 25.92 \\
\hline Total & 54 & 100 \\
\hline
\end{tabular}

Table.2.2 Distribution of MRSA among gender

\begin{tabular}{|l|l|l|l|l|l|}
\hline S.aureus & \multicolumn{2}{|c|}{ Male } & \multicolumn{2}{c|}{ Female } & Total \\
\cline { 2 - 6 } & Number & Percentage(\%) & Number & Percentage(\%) & \\
\hline MRSA & 30 & 55.56 & 24 & 44.44 & 54 \\
\hline
\end{tabular}

Table.3 Percentage of MRSA isolated from clinical samples

\begin{tabular}{|l|l|l|}
\hline \multirow{2}{*}{ Specimen } & \multicolumn{2}{l|}{ MRSA } \\
\cline { 2 - 3 } & Total & Percentage(\%) \\
\hline Pus & 24 & 44.44 \\
\hline Sputum & 6 & 11.11 \\
\hline Urine & 6 & 11.11 \\
\hline Blood & 10 & 18.53 \\
\hline Tracheal aspirate & 1 & 1.85 \\
\hline Drain & 6 & 11.11 \\
\hline Ascitic fluid & 1 & 1.85 \\
\hline Total & 54 & 100 \\
\hline
\end{tabular}

Table.4 Percentage of distribution of MRSA in wards

\begin{tabular}{|l|l|l|}
\hline \multicolumn{1}{c|}{ Ward } & \multicolumn{2}{c|}{ MRSA } \\
\cline { 2 - 3 } IMCU & Total & Percentage(\%) \\
\hline Surgery & 15 & 27.78 \\
\hline Orthopaedics & 18 & 33.33 \\
\hline Burns ward & 10 & 18.52 \\
\hline Urology & 3 & 5.56 \\
\hline Thoracic Medicine & 1 & 1.85 \\
\hline Dermatology & 1 & 1.85 \\
\hline Nephrology & 5 & 9.26 \\
\hline Ophthalmology & - & - \\
\hline Total & 1 & 1.85 \\
\hline
\end{tabular}


Table.5 Antibiogram of MRSA

\begin{tabular}{|l|c|c|}
\hline \multirow{2}{*}{ Antibiotic } & \multicolumn{2}{|c|}{ MRSA } \\
\cline { 2 - 3 } & Sensitive & Resistant \\
\hline Penicillin & 0 & 54 \\
\hline Cefoxitin & 0 & 54 \\
\hline Clinthromycin & 33 & 21 \\
\hline Gentamicin & 35 & 19 \\
\hline Amikacin & 36 & 18 \\
\hline Ciprofloxacin & 39 & 15 \\
\hline Cotrimoxazole & 37 & 17 \\
\hline Tetracycline & 35 & 19 \\
\hline Cephalexin & 0 & 22 \\
\hline Vancomycin & 54 & 54 \\
\hline Linezolid & 54 & 0 \\
\hline Teicoplanin & 54 & 0 \\
\hline
\end{tabular}

Among the $100 \mathrm{~S}$. aureus isolated from clinical samples, $46 \%$ was found to be MSSA and $54 \%$ was found to be MRSA isolates which was comparable with the study conducted by Majumer et al., from Assam, observed the prevalence of MRSA to be $52.9 \%$ Maximum number of MRSA were more than 60 years i.e.14 isolates $(25.92 \%)$ followed by age group of 41-50 years i.e. 11 isolates $(20.37 \%)$.Males outnumbered the females in the rate of isolation of MRSA. The sex ratio (male:female) for MRSA was $1.25: 1$. This was similar to the study by Sharma et al., where males $30 \%$ constituted most of the MRSA isolates while $10 \%$ was from females.

Among the $54 \%$ of MRSA isolated, $44.44 \%$ were from pus, $18.53 \%$ from blood, $11.11 \%$ each from sputum, urine and drain and $1.85 \%$ each from Ascitic fluid and tracheal aspirate which was comparable to the study by Terry Ali et al., where majority of the MRSA isolates were from pus $(21.4 \%)$.

Among the 54\% of MRSA isolated, 33.33\% were from Surgery followed by $27.78 \%$ from
IMCU, 18.52\% from Orthopaedics,9.26\% from Dermatology and $5.56 \%$ from Burns ward which was comparable with the study by Arora et al., who had found highest prevalence from surgical units (54.8\%). Among the MRSA strains isolated, all the isolates were resistant to Penicillin and Cephalexin, followed by Tetracycline (22 isolates), Erythromycin (21 isolates), Clindamycin and Cotrimoxazole 19 isolates each, Gentamicin (18 isolates), Ciprofloxacin (17 isolates) and Amikacin (15 isolates). All the isolates were sensitive to Vancomycin, Linezolid and Teicoplanin. Inducible Clindamycin resistance was detected in 13 isolates (24\%) among MRSA isolates.

This study highlights the prevalence of MRSA among clinical samples especially in hospitalized patients. Antibiogram of Methicillin sensitive and resistant isolates differs and susceptibility testing is mandatory for clinical isolates of $S$. aureus before initiation of treatment as few antibiotics exist for serious MRSA infections. An approach to eliminate MRSA in the hospitals and community needs to be integrated by creating 
awareness among people and good hygienic practices and effective barrier precautions are to be adapted to prevent further transmission.

\section{Acknowledgement}

The authors gratefully acknowledge The Dean, Tirunelveli Medical College Hospital, Tirunelveli, Tamil Nadu and The Staff of Microbiology, Tirunelveli Medical College Hospital.

\section{References}

Arora, S., Devi, P., Arora, U., Devi, B. (2010) Prevalence of methicillin-resistant Staphylococcus aureus (MRSA) in a tertiary care hospital in Northern India. J Lab Physicians. 2(2):78-81.

Blot, S.I., Vandewounde, K.H., Hoste, E.A., Colardyn, F.A. (2002) Outcome and attributable mortality in critically ill patients with bacteremia involving methicillin susceptible and methicillinresistant Staphylococcus aureus. Arch Inter Med. 162(19):2229-35.

Chambers, H.F. (1997) Methicillin resistance in staphylococci: molecular and biochemical basis and clinical implications. Clinical Microbiology Rev. 10(4): 781-91.

Clinical and Laboratory Standards Institute (CLSI). (2009) Performance standards for antimicrobial susceptibility testing, 18th informational supplement. Wayne, PA: Clinical and Laboratory Standards Institute.M100-S18.

Majumder, D., Bordoloi, J.N.S., Phukan, A.C., Mahanta, J. (2001) Antimicrobial susceptibility pattern among Methicillin resistant Staphylococcus isolates in Assam. Ind. J. Med. Microbiol. 19(3): 138-140.

Rajesh Bhatia, Rattan Lal Ichhpujani. (2008) Essentials of Medical Microbiology, Fourth edition, Part V. 5:140-145.

Salgado, C.D., Farr, B.M., Calfee, D.P. (2003) Community acquired methicillin resistant Staphylococcus aureus: a meta-analysis of prevalence and risk factors. Clinical Infectious Diseases. 36(2):131-9.

Sharma, S., Mall, A. (2011) The Prevalence, antibiogram and characterization of Methicillin resistant Staphylococcus aureus among the patients from the Doon valley hospitals. African $\mathbf{J}$ Microbiol Res. 5(21): 3446-51.

Terry Alli, O.A., Ogbolu, D.O., Mustapha, J.O., Akinbami, R., Ajayi, A.O. The non - association of Panton- Valentine leukocidin and mecA genes in the genome of Staphylococcus aureus from hospitals in South Western Nigeria. Ind J Med Microbiology. 30(2): 159-64.

\section{How to cite this article:}

Uma Maheswari, R., B. Cinthujah, G. Sucilathangam and Revathy, C. 2019. Prevalence and Antibiotic Resistance Pattern of Methicillin Resistant Staphylococcus aureus Isolates in a Tertiary Care Hospital. Int.J.Curr.Microbiol.App.Sci. 8(02): 587-592. doi: https://doi.org/10.20546/ijcmas.2019.802.066 